In der Zeitschrift für Literaturwissenschaft und Linguistik (LiLi) 129 ist ein Beitrag von Paul Irvin Anderson (S. 123-137) erschienen, in dem er sich kritisch mit der gegenwärtigen Editionspraxis im Allgemeinen und mit der großen Fontane-Ausgabe des Aufbau-Verlages im Besonderen auseinandersetzt. Dazu haben uns der Aufbau-Verlag und der Herausgeber des Stechlin, Klaus-Peter Möller, die beiden folgenden Stellungnahmen geschickt. Es versteht sich, daß alle drei Beiträge die Meinung der betreffenden Autoren, nicht unbedingt der Herausgeber von LiLi, widerspiegeln, und es sei noch einmal daran erinnert, daß die Rubrik »Labor «, wie es weiter oben heißt, »offen auch für zugespitzte Stellungnahmen«ist.

Die Herausgeber

\title{
Magdalena Frank, Aufbau-Verlag Berlin
}

Stellungnahme zu P. I. Anderson

Wir bedauern, daß die Zeitschrift dem Beitrag so viel Platz eingeräumt hat, der über eine punktuelle Kritik am Stechlin-Kommentar von Klaus-Peter Möller die Große Brandenburger Ausgabe (GBA) insgesamt in Mißkredit zu bringen sucht, im Sinne der Überschrift »Verpfuschte Klassikerpflege am Beispiel Fontane «. Pauschal abschätzige Urteile wechseln mit widersprüchlichen Feststellungen und Formulierungen, die die Edition als solche desavouieren, was um so bedauerlicher ist, als der Verfasser selbst Fontane-Forscher ist.

$\mathrm{Da}$ ein solches Großprojekt einer kritischen Werkausgabe, von der seit 199531 Bände vorgelegt wurden, nicht mit ein paar salopp sein sollenden Sprüchen zu disqualifizieren ist, liegt auf der Hand, zumal die GBA als einzige Fontane-Edition mit gesichertem Text und umfassendem Kommentar längst ihre Wirkung tut, andererseits weiterhin auf die Unterstützung nicht nur durch die Käufer und Benutzer, sondern auch durch die Medien und nicht zuletzt durch die Fontane-Forschung selbst und die Editionswissenschaft angewiesen ist. Die Ausgabe, die die Bedürfnisse eines breiteren Lesepublikums wie die Interessen der Fontane-Spezialisten bedient und insofern die Tradition der großen Leseausgaben des Aufbau-Verlages fortsetzt, ist eine gewaltige Investition. Was gebraucht und erwartet wird, sind kompetentes Urteil und öffentliche Ermutigung statt desorientierender, höchst subjektiver Schmähkritik und pauschaler Herabsetzung.

Auf die seltsame Frage und ihre ebenso irritierende Beantwortung: »Was kann man mit einer solchen Ausgabe anfangen außer den Romantext zitieren? «, können wir nur antworten: Sie vor allem lesen und den Kommentar mit Gewinn zur Kenntnis nehmen.

Zeitschrift für Literaturwissenschaft und Linguistik 131 (2003) 